\title{
PERBEDAAN KONSENTRASI STARTER TERHADAP TOTAL ASAM LAKTAT YOGHURT TERSUBTITUSI SARI BUAH LIMUS (Mangifera foetida)
}

\author{
Mia Muhafilah ${ }^{1)}$, Anna Fitri Hindriana ${ }^{2)}$, Haruji Satianugraha ${ }^{3)}$ \\ ${ }^{1}$ Pendidikan Biologi, FKIP, Universitas Kuningan \\ Email : muhafilahmia@gmail.com \\ ${ }^{2}$ Pendidikan Biologi, FKIP, Universitas Kuningan \\ Email : anna@uniku.ac.id \\ ${ }^{3}$ Pendidikan Biologi, FKIP, Universitas Kuningan \\ Email : haruji.satianugraha@uniku.ac.id
}
APA Citation: Muhafilah, M., Hindriana, A.F., \& Satianugraha, H. (2019). Perbedaan Konsentrasi Starter Terhadap Total Asam Laktat Yoghurt Tersubtitusi Sari Buah Limus (Mangifera foetida). Quagga: Jurnal Pendidikan dan Biologi, 11(1), 12-19. doi: 10.25134/quagga.v11i1.1511.

Received: 28-11-2018

Accepted: 11-12-2018

Published: 04-01-2019

\begin{abstract}
Abstrak: Buah limus (Mangifera foetida) yang kurang dimanfaatkan sebagai buah konsumsi, dengan cara disubtitusi dapat menambah nilai dan mengangkat buah lokal ini, subtitusi sari buah limus (Mangifera foetida) akan menambah cita rasapada yoghurt dan meningkatkan kadar total asam laktat. Tujuan penelitian ini adalah mengetahui perbedaan konsentrasi starter dan penambahan sari buah limus (Mangifera foetida) terhadap kualitas yoghurt serta pengaruhnyaterhadap kadar asam laktat.Penelitian ini dilakukan dengan 4 perlakuan yaitu starter 1\%, 3\%, 5\% dan kontrol, serta penambahan sari buah limus (Mangifera foetida) sebanyak 10\%.Difermentasi dalam inkubator dengan suhu $37^{\circ} \mathrm{C}$ selama 24 jam. Hasil penelitian menunjukan konsentrasi $1 \%$ asam laktat tertinggi adalah 1,62\%, konsentrasi 3\% asam laktat tertinggi adalah 1,71\%, konsentrasi $5 \%$ asam laktat tertinggi adalah 1,80\%, dan konsentrasi kontrol asam laktat tertinggi adalah 1,24\%. Panelis lebih menyukai aroma yoghurt dengan konsentrasi starter 3\%, rasa yoghurt dengan konsentrasi kontrol, tekstur yoghurt dengan konsentrasi 3\%, dan warna yoghurt dengan konsentrasi 1\%. Perbedaan konsetrasi starter yoghurt tidak berpengaruh secara signifikan terhadap total asam laktat, aroma, rasa, tekstur/kekentalan, dan warna. Total asam laktat pada yoghurt meningkat setelah diberi sari buah limus (Mangifera foetida).Penambahan sari buah Limus bermanfaat untuk meningkatkan cita rasa dan meningkatkan nilai gizi yoghurt serta menggantikan essens atau perisa makanan.
\end{abstract}

Kata Kunci :Mangifera foetida, total asam laktat, yoghurt.

\begin{abstract}
Limus fruit (Mangifera foetida) which is underutilized as a fruit consumption, but by substitution it can add value and lift this local fruit, substitution of limus fruit juice (Mangifera foetida) will add flavor to yogurt and increase the total level of lactic acid. The purpose of this study was to determine the difference in starter concentration and the addition of limus fruit juice (Mangifera foetida) to the quality of yogurt and its effect on lactic acid levels. This study was conducted with 4 treatments, namely starter 1\%, 3\%, 5\% and control, and the addition of limus fruit juice (Mangifera foetida) by $10 \%$. Fermented in an incubator at $37^{\circ} \mathrm{C}$ for 24 hours. The results showed the highest concentration of $1 \%$ lactic acid was $1.62 \%$, the highest concentration of $3 \%$ lactic acid was $1.71 \%$, the highest concentration of $5 \%$ lactic acid was $1.80 \%$, and the highest concentration of lactic acid control was $1.24 \%$. Panelists prefer the aroma of yogurt with a concentration of $3 \%$ starter, yogurt flavor with control concentration, yogurt texture with a concentration of $3 \%$, and yogurt color with a concentration of $1 \%$. The difference in yogurt starter concentrations does not significantly affect total lactic acid, aroma, taste, texture / thickness, and color. The total lactic acid in yogurt increases after being given limus fruit juice (Mangifera foetida). The addition of Limus fruit juice is useful for enhancing flavor and increasing the nutritional value of yogurt and replacing food essences or flavorings.
\end{abstract}

Keywords: Mangifera Foetida, total lactic acid, yogurt.

\section{PENDAHULUAN}

Yoghurt dapat dibuat dari berbagai jenis susu, termasuk susu kacang kedelai. Yoghurt merupakan salah satu olahan susu yang diproses melalui proses fermentasi susu yang bersifat semi padat dengan penambahan kultur organisme yang baik, salah satunya yaitu bakteri asam laktat (Verawati, 2009: 2).

Yoghurt mengandung probiotik dan prebiotik, memiliki banyak efek yang bermanfaat seperti 
menambah kekebalan sistem imun, membantu mencerna laktosa dan anti peradangan (Adolfsson et al, 2004, dalam Joung et al. 2016). Selain itu, yoghurt memiliki efek menguntungkan pada fungsi usus, seperti mengurangi penyerapan kolesterol, mengurangi tekanan darah, dan memperbaiki gangguan usus dan penyakit kronis. Laktosa dalam susu diubah menjadi asam laktat selama fermentasi, sehingga semua orang dapat mengkonsumsi yoghurt (Nguyen \& Hwang, 2016).

Yoghurt pada umumnya terasa asamdan untuk menambah cita rasa maka ditambahkan ekstrak sari atau bubur buah atau tumbuhan. Buah yang biasa digunakan diantaranya strowberi, bluberi, dan rasberi, yaitu buahbuahan yang memberikan warna alami dan rasa serta senyawa bioaktif. Efek dari berbagai jenis bahan tumbuhan ditambahkan sebagai bahan fungsional pada sifat kualitas dan antioksidan (Nguyen \& Hwang, 2016). Sari atau bubur buah dan yoghurt mengandung berbagai macam senyawa bioaktif sehingga dapat meningkatkan dan menurun selama proses pematangan, penyimpanan, dan pengolahan (Fernandez \&André, 2017).

Penambahan sari buah Limus pada yoghurt diperkirakan dapat meningkatkan total asam laktat sehingga buah ini semula kurang dimanfaatkan sebagai buah konsumsi dapat dimanfaatkan dan menambah nilai jual buah lokal. Buah limus (Mangifera foetida) merupakan jenis mangga yang banyak terdapat masyarakat, wanginya yang sangat harum karena memiliki kandungan senyawa aromatik yaitu alkaloid, sehingga dapat meningkatkan aroma dan cita rasa pada yoghurt itu sendiri. Mangga yang satu ini jarang dikonsumsi oleh banyak orang, dikarenakan serat daging buah yang begitu banyak jika dibandingkan dengan dagingnya sehingga pemanfaatnnya kurang diberdayakan dan menyebabkan banyaknya limus (Mangifera foetida) yang membusukmengakibatkan daya jualnya sangat rendah, sementara ini masyarakat hanya memanfaatkan kayunya saja untuk bahan bangunan.

Subtitusi limus pada yoghurt diharapkan dapat mempengaruhi hasil fermentasi Streptococcus thermophillus danLactobacillus $d$. bulgaricus terutama kadar asam laktatnya agar dapat memenuhi syarat SNI 2981-2009 bahwa kandungan asam laktat dalam yoghurt berkisar antara $0,5-2,0 \%$.

\section{Rumusan Masalah}

Berdasarkan latar belakang di atas dapat dirumuskan permasalahan sebagai berikut:

1. Apakah ada perbedaan konsentrasi starter yoghurt terhadap total asam laktat?

2. Apakah dengan subtitusi sari buah limus (Mangifera Foetida) dapat mempengaruhi total asam laktat?

3. Apakah dengan adanya perbedaan starter dan subtitusi buah limus pada yoghurt akan menambah cita rasa?

\section{METODOLOGI PENELITIAN Material}

Bahan yang digunakan dalam pembuatan yohurt adalah susu segar yang dibeli dari Koperasi Petani Cipari, buah limus (Mangifera foetida) harus dalam kondisi matang dan segar yang dibeli dari pedagang buah di Pasar Kepuh, starter 1\%, 3\%, dan 5\% hasil biakan F0 dari starter serbuk yang dibeli secara online di tokopedia.com. Bahan untuk titrasi menggunakan $\mathrm{NaOH}$ proanalis, indikator $\mathrm{PP}$, dan aquades.

Alat yang digunakan dalam pembuatan sari buah, yoghurt dan titrasi adalah panci, spatula, kompor, inkubator, autoklef, botol kultur, pisau, blender, saringan, termometer, gelas beker, gelas ukur, corong, labu ukur $100 \mathrm{~mL}$, tabung Erlenmeyer $100 \mathrm{~mL}$, pipet tetes, kertas filtrat, timbangan analitik, buret dan statif.

Pembuatan sari buah limus (Mangifera foetida) dan Yoghurt

Kulit buah dikupas, lalu daging buah dipotong kecil untuk dihaluskan menggunakan blender dan tambahkan air secukupnya. Limus banyak mengandung serat buah pada dagingnya maka perlu

disaring supaya didapatkan sari buah tanpa serat dari daging buah.

Sari buah limus (Mangifera foetida) disubtitusi sebanyak $10 \%$ pada susu segar yang telah dimasak dengan api kecil dan diaduk hingga suhu tidak lebih dari $85^{\circ} \mathrm{C}$, susu diturunkan suhunya hingga mencapai $35^{\circ} \mathrm{C}$, kemudian ditambahkan starter yoghurt hasil biakan F0 dari starter serbuk dengan konsentrasi $1 \%$, 3\%, dan $5 \%$, lalu difermentasi dalam inkubator dengan suhu $37^{\circ} \mathrm{C}$ selama 24 jam.

\section{Titrasi yoghurt}

Sampel dimasukan sebanyak 10 gram ke dalam labu ukur $100 \mathrm{~mL}$, tambahkan aquades sampai tanda batas, homogenkan, saring, filtrat diambil $10 \mathrm{~mL}$, masukan ke dalam tabung 
Quagga: Jurnal Pendidikan dan Biologi

Volume 11, Nomor 1, Januari 2019

Erlenmeyer, tetesi 2-3 tetes indikator PP, sampel dititrasi dengan larutan $0,1 \mathrm{~N} \mathrm{NaOH}$ proanalis hingga warna tidak berubah kembali selama 30 detik. jumlah $\mathrm{NaOH}$ yang terpakai dihitung menggunakan rumus keasaman (\%).

Rumus total asam laktat:

$$
(\%)=\frac{\mathrm{V} \times \mathrm{N} \times 90}{\mathrm{~W}} \times 100 \%
$$

Ket: $\mathrm{V}=$ volume larutan $\mathrm{NaOH}(\mathrm{mL})$

$\mathrm{N}=$ normalitas larutan $\mathrm{NaOH}(0,1 \mathrm{~N})$

$\mathrm{W}=$ bobot contoh $(\mathrm{mg})$

$90=$ bobot setara asam laktat

*sumber: Badan Standar Nasional (BSN), 2009.

Standar Nasional Indonesia Yoghurt, SNI 2981:2009

\section{HASIL DAN PEMBAHASAN Hasil}

Berdasarkan Tabel 1. diketahui bahwa yoghurt yang disubtitusi sari buah limus memiliki total asam laktat yang tinggi dibandingkan dengan yoghurt kontrol yaitu sebanyak $1,02 \%$. Rata-rata total asam laktat tertinggi adalah dengan konsentrasi starter 5\% yaitu sebanyak $1,57 \%$ dan rata-rata total asam laktat terendah adalah dengan konsentrasi starter $1 \%$ yaitu sebanyak $1,4 \%$. Pada konsentrasi $1 \%$ asam laktat tertinggi adalah $1,62 \%$ dipengulangan pertama, konsentrasi $3 \%$ asam laktat tertinggi adalah $1,71 \%$ dipengulangan pertama, konsentrasi $5 \%$ asam laktat tertinggi adalah $1,80 \%$ dipengulangan pertama. Hasil data tersebut sesuai dengan kandungan asam laktat yang dipersyaratkan oleh SNI 2981-2009, yaitu antara $0,5 \%-2,0 \%$.

Total asam laktat yang dihasilkan dari konsentrasi starter berbeda dapat dilihat pada Gambar 1.

Tabel 1. Hasil analisis total asam laktat (\%)

\begin{tabular}{ccccc}
\multicolumn{5}{c}{ yoghurt } \\
\hline \% & $\mathbf{t 1}$ & $\mathbf{t 2}$ & $\mathbf{t 3}$ & $\mathbf{K}$ \\
\hline r1 & 1,62 & 1,71 & 1,80 & 0,91 \\
r2 & 1,35 & 1,44 & 1,53 & 0,74 \\
r3 & 1,26 & 1,26 & 1,35 & 0,8 \\
r4 & 1,44 & 1,53 & 1,62 & 1,11 \\
r5 & 1,35 & 1,35 & 1,44 & 1,24 \\
r6 & 1,44 & 1,53 & 1,53 & 1,23 \\
r7 & 1,44 & 1,62 & 1,71 & 1,04 \\
r8 & 1,35 & 1,53 & 1,62 & 1,20 \\
r9 & 1,35 & 1,44 & 1,53 & 0,9 \\
\hline Jumlah & $\mathbf{1 2 , 6}$ & $\mathbf{1 3 , 4 1}$ & $\mathbf{1 4 , 1 3}$ & $\mathbf{9 , 1 7}$ \\
\hline Rata- & $\mathbf{1 , 4}$ & $\mathbf{1 , 4 9}$ & $\mathbf{1 , 5 7}$ & $\mathbf{1 , 0 2}$ \\
rata & & & & \\
\hline
\end{tabular}

p-ISSN 1907-3089, e-ISSN 2651-5869

https://journal.uniku.ac.id/index.php/quagga

Keterangan:

t1: yoghurt dengan starter $1 \%$

t2: yoghurt dengan starter 3\%

t3: yoghurt dengan starter 5\%

$\mathrm{K}$ : yoghurt kontrol tanpa sari buah

$\mathrm{r}$ : pengulangan dari setiap $\mathrm{t}$ dan $\mathrm{K}$

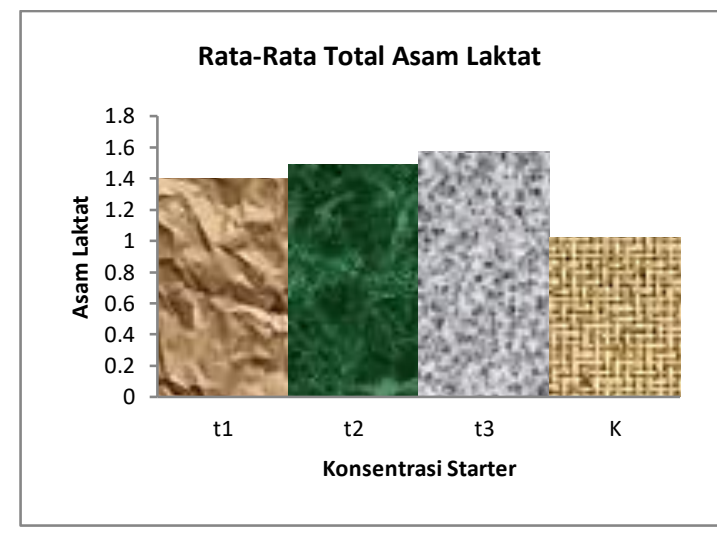

Gambar 1.Rata-rata total asam laktat yoghurt tersubtitusi sari buah limus (Mangifera foetida)

Penambahan sari buah limus (Mangifera foetida) telah menambah total asam laktat pada yoghurt dibandingkan dengan kontrol. Kualitas yoghurt dapat dilihat dari kandungan asam laktatnya, pada proses fermentasi laktosa diubah menjadi asam laktat oleh bakteri Lactobacillus bulgaricus dan Streptococcus termophilus sehingga menambah citra rasa yoghurt.Dari hasil titrasi didapatkan total asam laktat yoghurt tertinggi adalah pada konsentrasi 5\%.

Pembuatan yoghurt subtitusi sari buah limus (Mangifera foetida) yang disukai konsumen menunjukan hasil yang berbeda. Indikator yang diujikan pada konsumen yaitu aroma, rasa, tekstur/kekentalan dan warna. Adapun hasil pentabulasian data mengenai rata-rata untuk aroma, rasa, tekstur/kekentalan, dan warna pada yoghurt subtitusi sari buah limus (Mangifera foetida) dengan konsentrasi starter yang berbeda dapat dilihat pada Tabel 2.

Tabel2.Hasil tabulasi rata-rata mengenai aroma, rasa, tekstur/kekentalan dan warna yoghurt

\begin{tabular}{lcc}
\hline $\begin{array}{c}\text { Karakter } \\
\text { yang Diuji }\end{array}$ & Konsentrasi & $\begin{array}{c}\text { Rata-rata } \\
(\boldsymbol{\%})\end{array}$ \\
\hline \multirow{4}{*}{ Aroma } & $1 \%$ & 2.37 \\
& $3 \%$ & 2.62 \\
& $5 \%$ & 2.60 \\
Rasa & $\mathrm{K}$ & 2.42 \\
& $1 \%$ & 2.10 \\
& $3 \%$ & 2.38 \\
& $5 \%$ & 2.60
\end{tabular}


Quagga: Jurnal Pendidikan dan Biologi Volume 11, Nomor 1, Januari 2019

\begin{tabular}{ccc}
\hline $\begin{array}{c}\text { Karakter } \\
\text { yang Diuji }\end{array}$ & Konsentrasi & $\begin{array}{c}\text { Rata-rata } \\
(\boldsymbol{\%})\end{array}$ \\
\hline \multirow{4}{*}{ Tekstur } & $\mathrm{K}$ & 2.92 \\
& $1 \%$ & 2.32 \\
& $3 \%$ & 2.78 \\
& $5 \%$ & 2.38 \\
Warna & $\mathrm{K}$ & 2.52 \\
& $1 \%$ & 2.57 \\
& $3 \%$ & 2.55 \\
& $5 \%$ & 2.55 \\
& $\mathrm{~K}$ & 2.33 \\
\hline
\end{tabular}

Keterangan:

$\mathrm{K}$ : yoghurt kontrol tanpa sari buah

Dari hasil tabel diatas terlihat rata-rata tertinggi mengenai aroma yoghurt terdapat pada konsentrasi starter 3\%, mengenai rasa yoghurt terdapat pada konsentrasi kontrol, mengenai tekstur yoghurt terdapat pada konsentrasi 3\%, dan mengenai warna yoghurt terdapat pada komposisi $1 \%$.

\section{a. Hasil tabulasi mengenai aroma}

Pada uji organoleptik aroma, panca indra yang digunakan adalah penciuman yaitu hidung. Untuk rata-rata hasil uji organoleptik terhadap aroma yoghurt subtitusi sari buah limus dapat dilihat pada Gambar 2:

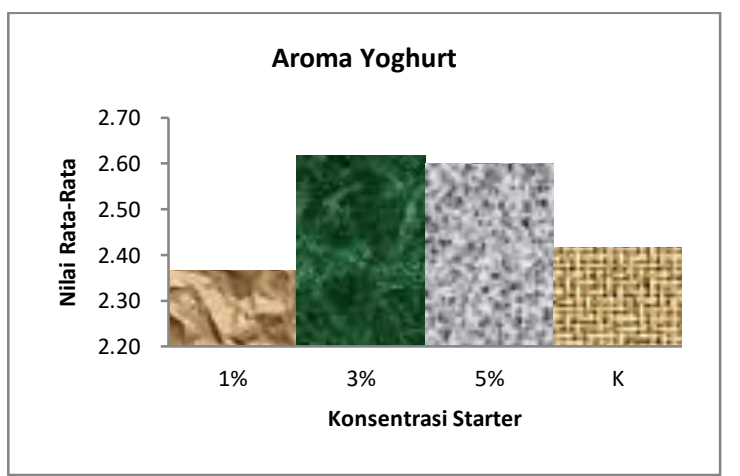

Gambar 2. Hasil tabulasi rata-rata aroma yoghurt

Dari hasil uji organoleptik yoghurt tercium aroma khas yoghurt dan wangi limus yang menyegarkan. Dibandingkan dengan kontrol aroma yoghurt lebih wangi dengan subtitusi sari buah dari pada tanpa subtitusi sari buah. Responden lebih menyukai aroma yoghurt dengan konsentrasi starter 3\%.

\section{b. Hasil tabulasi mengenai rasa}

Pada uji organoleptik rasa, panca indra yang digunakan adalah lidah yang mana ditekankan pada tingkat keenakan rasa yoghurt. Untuk rata-rata hasil uji organoleptik terhadap
p-ISSN 1907-3089, e-ISSN 2651-5869

https://journal.uniku.ac.id/index.php/quagga

rasa yoghurt subtitusi sari buah limus dapat dilihat pada gambar 3:

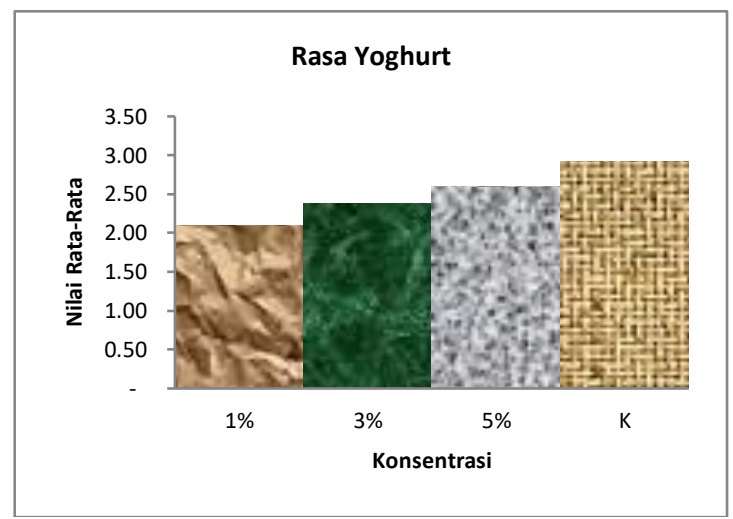

Gambar 3. Hasil tabulasi rata-rata rasa yoghurt

Dari hasil uji organoleptik yoghurt terasa asam khas yoghurt, dibandingkan dengan kontrol, rasa yoghurt lebih asam dengan subtitusi sari buah dari pada tanpa subtitusi sari buah. Responden lebih menyukai rasa yoghurt dengan perlakuan kontrol, hal ini terjadi karena kebiasaan setiap orang jika mengkonsumsi yoghurt tanpa aroma melainkan hanya essens atau perisa makanan.

\section{c. Hasil tabulasi mengenai tekstur/kekentalan}

Pada uji organoleptik tekstur, panca indra yang digunakan adalah lidah yang mana ditekankan pada tingkat kelembutan dan kekentalan yoghurt. Untuk rata-rata hasil uji organoleptik terhadap tekstur yoghurt subtitusi sari buah limus dapat dilihat pada gambar 4:

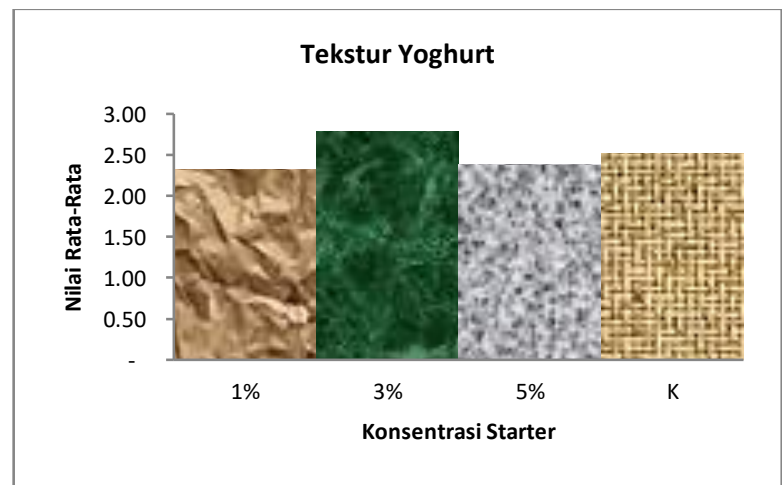

Gambar 4. Hasil tabulasi rata-rata tekstur yoghurt

Dari hasil uji organoleptik tekstur yoghurt terasa lembut semi padat khas yoghurt. Responden lebih menyukai tekstur yoghurt dengan konsentrasi starter 3\%.

d. Hasil tabulasi mengenai warna

Untuk rata-rata hasil uji organoleptik terhadap warna yoghurt subtitusi sari buah limus dapat dilihat pada gambar 5: 
Quagga: Jurnal Pendidikan dan Biologi

Volume 11, Nomor 1, Januari 2019

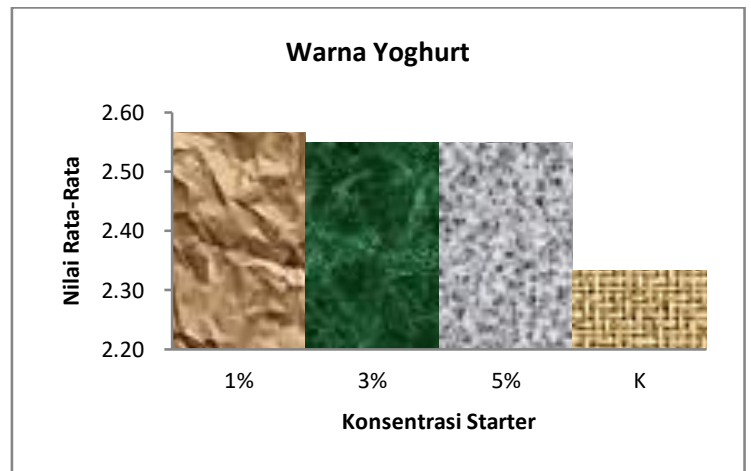

Gambar 5. Hasil tabulasi rata-rata warna yoghurt

Dari hasil uji organoleptik yoghurt dengan penambahan sari buah berwarna putih tulang, sedangkan yoghurt tanpa subtitusi sari buah terlihat putih bersih seperti susu. Responden lebih menyukai warna yoghurt dengan konsentrasi starter $1 \%$.

\section{Pembahasan}

Limus (Mangifera Foetida) yang memiliki warna kulit buah berwarna hijau gelap dan terdapat bercak coklat dan hitam tidak memiliki warna mengkilap seperti mangga pada umumnya, sedangkan daging buah seperti mangga lainya dan memiliki aroma yang harum serta pada dagingnya terdapat serat buah yang banyak. Aroma wangi ini dipengaruhi oleh gas etilen yang berperan dalam proses pematangan buah yaitu ketika kandungan gas dalam ruang antar sel meningkat tajam sampai sekitar 0,1-1 $\mu l$ per liter (Salisbury \& Ross, 1995).

Buah limus (Mangifera Foetida) memiliki nilai gizi yang baik, akan tetapi kalah oleh jenis mangga lainnya karena getahnya banyak, seratnya lebih kasar dan memiliki rasa yang asam (Nurviana, 2016). Dibuatnya sari buahbertujuan agar yoghurt lebih segar dan aromanya tercium lebih harum.

Susu yang dipanaskan dengan api kecil dan terus diaduk hingga suhu tidak lebih dari $85^{\circ} \mathrm{C}$ bertujuan agar kandungan pada susu tidak rusak, mengurangi mikroorganisme patogen agar terbunuh hingga batas aman untuk kesehatan konsumen. Setelah susu dipanaskan, kemudian susu dibiarkan agar suhunya turun hingga $37^{\circ} \mathrm{C}$ karena $S$. termophilus hanya dapat tumbuh pada suhu antara $35-53^{\circ} \mathrm{C}$ dan L. burgaricus dapat tumbuh pada suhu $40-44^{\circ} \mathrm{C}$ (Sfakianakis \& Tzia. 2014). Setelah limus, susu dan starter dicampur dan difermentasi dengan inkubasi selama 24 jam. Jika waktu fermentasi lebih lama akan menambah asam laktat (Kartikasari \& Nisa.2014).
p-ISSN 1907-3089, e-ISSN 2651-5869

https://journal.uniku.ac.id/index.php/quagga

Dalam proses fermentasi $S$. thermophillus dan L. bulgaricus akan bersimbiosis memecah laktosa menjadi asam laktat, asam laktat yang tinggi dapat mencegah pertumbuhan bakteri pembusuk seperti Clostridium dan Staphylococcus (Rahayu, et al 1983 dalam Afwan et al. 2016). Asam amino dan peptida kecil diproduksi oleh bakteri asam laktat yang merangsang pertumbuhan $S$. termophillus, sedang metabolisme $S$. termophillus seperti karbon dioksida dan asam formik merangsang pertumbuhan Lactobacillus (Phillips et al, 2006 dalamJoung et al. 2016).

Proses pertumbuhan bakteri starter dalam pembuatan yoghurt diawali dengan peningkatan laju pertumbuhan $S$. thermophillus yang memproduksi asam laktat pada $\mathrm{pH}$ rendah untuk meningkatkan $L$. bulgaricus memproduksi asam laktat yang menimbulkan penurunan $\mathrm{pH}$ (Kartikasari \& Nisa. 2014). Beberapa bahan tumbuhan mengandung senyawa antimikroba yang dapat mempengaruhi pertumbuhan bakteri asam laktat (Nguyen \& Hwang. 2016).

Tujuan penelitian kadar asam laktat pada yoghurt adalah untuk memastikan yoghurt yang akan diberikan kepada panelis memiliki kualitas yang telah mencapai SNI 2981-2009. Total asam laktat berdasarkan Tabel 1 menunjukan bahwa penambahan sari buah dibandingkan dengan kontrol berbeda dan menunjukan peningkatan, yaitu dengan rata - rata $1,4 \%$ pada konsentrasi $1 \% ; 1,49 \%$ pada konsentrasi $3 \% ; 1,57 \%$ pada konsentrasi $5 \%$, dan $1,02 \%$ pada kontrol, walaupun secara statistik tidak menunjukan perbedaan yang signifikan.

Yoghurt dengan konsentrasi 5\% menunjukan peningkatan total asam laktat tertinggi yaitu $1,80 \%$ pada pengulangan pertama dan total asam laktat terendah yaitu $1,26 \%$ pada pengulangan ketiga. Sedangkan kontrol menunjukan total asam laktat tertinggi yaitu $1,24 \%$ pada pengulangan kelima dan total asam laktat terendah yaitu $0,74 \%$ pada pengulangan kedua. Total asam laktat seluruh sampel telah memenuhi syarat SNI 2981-2009. Perbedaan total asam laktat ini dikarenakan oleh perbedaan konsentrasi kultur starter yang diberikan pada susu serta perbedaan asam laktat kelompok eksperimen dan kontrol dikarena adanya penambahan sari buah limus (Mangifera foetida).

Selain itu berdasarkan rata-rata total asam laktat pada Tabel 1 dan Gambar 1 menunjukan yoghurt yang diberi sari buah limus (Mangifera foetida) memiliki total asam laktat yang lebih 
tinggi jika dibandingkan dengan kontrol, karena limus (Mangifera foetida) memiliki rasa yang asam dan meningkatkan rasa asam pada yoghurt sehingga mampu meningkatkan total asam laktat. Hal ini sesuai dengan pernyataan Jitoe et al. 1999 dalam Kartikasari \& Nisa (2014) bahwa penambahan sari buah limus (Mangifera foetida) menyebabkan total asam laktat meningkat, adanya penambahan sari buah menyebabkan peningkatan asam malat pada sari buah yang dapat dirombak oleh Lactobacillus menjadi asam laktat sehingga hal ini dapat menambah jumlah asam laktat pada yoghurt.

Proses fermentasi yang dilakukan oleh bakteri asam laktat dalam pemecahan laktosa menjadi asam laktat dapat mempengaruhi citarasa dari yoghurt yang dihasilkan. Seperti aroma dan rasa yang khas dari yoghurt yang dapat diterima oleh masyarakat. Secara organoleptik kandungan asetaldehida dan diasetil dengan rasio 1:1 memberikan aroma yoghurt yang disukai, kandungan asetildehida yang tinggi tidak memberikan rasa yoghurt yang baik, namun hal ini menjadi tidak bermakna pada perisa atau sari buah yang ditambahkan ke yoghurt karena didominasi oleh senyawa flavor yang ditambahan. Yoghurt yang terasa asam merupakan ciri khas dari hasil perkembangbiakan dari pencampuran bakteri yang berkembang dengan baik dan cepat serta menunjukan bahwa sudah terbentuknya asam laktat (Boyu, 2013 dalamAfwan et al. 2016). Penambahan sari buah dapat meningkatkan total asam lakta.

Peningkatan asam malat disebabkan oleh penambahan sari buah yang dirombak oleh Lactobacillus menjadi asam laktat, sehingga jumlah S. termophillus dan L. bulgariccus pada yoghurt juga dinyatakan bertambah. Kondisi ini sesuai dengan pernyataan Kuar dan Mishra (2003 dalam Nguyen \& Hwang. 2016) bahwa jumlah $S$. termophillus dan $L$. bulgariccus pada yoghurt dinyatakan meningkat dalam proporsi bubur mangga.

Konsentrasi starter yang berbeda pada setiap perlakuan menyebabkan jumlah bakterinya pun akan berbeda, jadi dengan penambahan sari buah limus yang menyumbang asam malat maka akan dirombak oleh bakteri menjadi asam laktat. Semakin banyak jumlah bakteri pada yoghurt maka asam laktat semakin tinggi, konsentrasi starter yang tinggi menyebabkan substrat asam malat yang dirombak oleh bakteri menjadi asam laktat semakin banyak dan rasa asam pada yoghurt pun semakin tinggi.Menurut Kosikowski dalamAfwan et al. (2016) tinggi rendahnya asam laktat dipengaruhi oleh kemampuan bakteri asam laktat yang ditentukan oleh jumlah dan jenis starter yang digunakan serta keadaan lingkungan fermentasi selama inkubasi.

Berdasarkan uji organoleptik menunjukan rata-rata kesukaan panelis terhadap yoghurt dalam hal aroma, rasa, tekstur/kekentalan dan warna tersaji pada Tabel 2 dimana panelis lebih menyukai aroma yoghurt dengan konsentrasi 3\% yang memiliki aroma yang lebih harum dibandingkan dengan kontrol tanpa adanya penambahan sari buah.

Rasa pada yoghurt dengan perlakuan kontrol dengan rata-rata 2,92 lebih disukai oleh panelis karena kebiasaan setiap orang jika mengkonsumsi yoghurt tanpa aroma melainkan hanya essens atau perisa makanan, selain itu karena yoghurt dengan penambahan sari buah limus memiliki rasa yang sangat asam dibandingkan dengan kontrol, pada yoghurt yang ditambahkan sari buah limus memiliki jumlah bakteri yang lebih banyak dan rasa yang lebih asam.

Tekstur/kekentalan yoghurt dengan konsentrasi 3\% lebih disukai oleh panelis, pada konsentrasi ini yoghurt memiliki tekstur yang tidak terlalu cair atau pun tidak terlalu padat. Semakin tinggikonsentrasi starter akan menyebabkan tekstur pada yoghurt semakin padat atau kental karena jumlah bakteri pada yoghurt semakin banyak sehingga menjadikan yoghurt lebih padat atau kental.

Warna pada yoghurt dengan konsentrasi $1 \%$ lebih disukai oleh panelis, yoghurt dengan konsentrasi $1 \%$ memiliki warna yang lebih segar dibandingkan dengan konsentrasi 3\%, dan 5\% yang memiliki warna yoghurt lebih keruh namun warna pada kontrol tidak berubah, mempunyai warna yang sama seperti warna susu.

\section{SIMPULAN}

Berdasarkan penelitian menunjukan perbedaan konsetrasi starter yoghurt tidak berpengaruh secara signifikan terhadap total asam laktat, aroma, rasa, tekstur/kekentalan, dan warna. Pemberian sari buah Limus (Mangirefa foetida) dapat meningkatkan total asam laktat dengan kadar sesuai persyaratan SNI. Panelis lebih menyukai aroma yoghurt dengan konsentrasi starter 3\%, rasa yoghurt dengan konsentrasi kontrol, tekstur yoghurt dengan 
Quagga: Jurnal Pendidikan dan Biologi

Volume 11, Nomor 1, Januari 2019

konsentrasi 3\%, dan warna yoghurt dengan konsentrasi $1 \%$.

\section{REFERENSI}

Anonim. Nilai Gizi Yoghurt.(Online) Tersedia: http://www.geocities.ws/mppatria/ygizi.htm (diakses tanggal 20 Agustus 2018).

Afwan, M.S., T. Gozali, D.Z. Arief. 2016. Karakteristik Yoghurt Tersubtitusi Sari Buah Naga (Hylocereus Polyrhizus) Pada Jenis Dan Konsentrasi Starter Yang Berbeda-Beda. Jurnal Penelitian Tugas Akhir.1-11.

Arena, M.P., Caggianiello G., Russo P. 2015. Functional Starter For Functional Yogurt. Foods. 4: 15 - 33 .

Astriana, D. 2014. Potensi Ubi Jalar (Ipomea batatas) Untuk Fortifikasi Pembuatan Sirup Yang Bercita Rasa. Skripsi. Fakultas Keguruan dan Ilmu Pendidikan, Universitas Kuningan, Kuningan. (Tidak dipublikasikan).

Badan Standar Nasional (BSN), 2009. Standar Nasional Indonesia Yoghurt, SNI 2981:2009.

Basalamah, N.A. 2017. Pengaruh Sutitusi Ekstrak Kedelai Terhadapa Karrakteristik Selulosa Bakteri Acetoacter Xylinum Dalam Pembuatan Nata de Sweet Potato. Skripsi. Fakultas Keguruan dan Ilmu Pendidikan, Universitas Kuningan, Kuningan. (Tidak dipublikasikan).

Fernandez, M.A. \& M. André. 2017. Potential Health Benefits Of Combining Yogurt And Fruit Based On Their Probiotic And Prebiotic Properties. American Society For Nutrition. 8: 1555 - 1645.

Hanafiah, K.A. 2014. Rancangan Percobaan Teori dan Aplikasi. Jakarta: Rajagrafindo Persada.

Handayani. 2018. Panduan Praktikum Biokimia Berbasis Vee Diagram. Kuningan: Pendidikan Biologi Universitas Kuningan.

Hasrudin \& N. Pratiwi. 2015. Mikrobiologi Industri. Bandung: Alfabeta.

Joung, J.Y., J.Y. Lee, Y.S. Ha. 2016. Enhanced Microbial, Functional and Sensory Properties of Herbal Yogurt Fermented with Korean Traditional Plant Extracts. Korea J Food Sci. An. 36 (1). 90 - 99.

Kartikasari, D.I. \& F.C. Nisa. 2014. Pengaruh Penambahan Sari Buah Sirsak Dan Lama Fermentasi Terhadap Karakteristik Fisik
p-ISSN 1907-3089, e-ISSN 2651-5869

https://journal.uniku.ac.id/index.php/quagga

dan Kimia Yoghurt. Jurnal Pangan dan Agroindustri. 2 (4): 239 - 248.

Michael, M., R.K. Phebus, K.A. Schmidt. 2010. Dampak Ektrak Tumbuhan Terhadap Viabilitas Lactobacillus Delbrueckii Ssp Bulgaricus Dan Streptococcus Thermophilus Pada Yoghurt Tanpa Lemak. International Dairy Journal Elsevier. 20: 665 - 672.

Nguyen, L. \& E.S. Hwang. 2016. Quality Characteristics And Antioksidant Activity Of Yogurt Supplemented With Aronia (Aronia melanocarpa) Juice. Prev. Nutr. Food Sci. 21 (4): 330 - 337.

Nurjanah, A.S. 2017. Pengaruh Konsentrasi Ragi Terhadap Kadar Alkohol Pada Pembuatan Brem Cair. Skripsi. Fakultas Keguruan dan Ilmu Pendidikan, Universitas Kuningan. Kuningan. (Tidak dipublikasikan).

Nurviana, V. 2016. Skrining Fitokimia dan Uji Aktivitas Antibakteri Ekstrak Etanol Biji Buah Bacang (Mangifera Foetida) Terhadap Escherichia coli. PharmaXplore: Jurnal Sains dan Ilmu Farmasi. 1 (2): 66-74.

Pelczar \& Chan. 2005. Dasar-Dasar Mikrobiologi I. Jakarta: Universitas Indonesia.

Permendikbud. 2016. Standar Proses Pendidikan Menengah, nomor 22.

Salisbury \& Ross. 1995. Fisiologi Tumbuhan: Jilid 3. Bandung: ITB.

Selvamuthukumaran, M. \& F. Khanum. 2016. Optimization of SeaBuckthorn Fruit Yogurt Formulation Using Response Surface Methodology. J Food Sci Technol. 52 (2): $831-839$.

Septiawan, R. 2011. Pembuatan Yoghurt Sinbiotik Menggunakan Bakteri Asam Laktat Indigenus Sebagai Pangan Fungsional Antidiare. Skripsi. Fakultas Teknologi Agricultur, Institut Pertanian Bogor, Bogor. (Tidak dipublikasikan).

Sfakianakis, P. \& C. Tzia. 2014. Conventional and Innovative Processing of Milk for Yogurt Manufacture; Development of Texture and Flavor: A Review. Foods. 3: 176-193.

Sudjana. 2005. Metode Statistik. Bandung: Tarsito.

Sugiyono. 2016. Metode Penelitian Pendidikan. Bandung: Alfabeta.

Sun, J.M. et al. 2015. Efek Mulberry Kering Pada Aktivitas Antoksida Dan 
Karakteristik Fermentasi Yoghurt Selama Penyimpanan Didinginkan. Korean J Food Sci. An. 35 (6). 897 - 814.

Supranto. 2009. Statistik Teori dan Aplikasi. Jakarta: Erlangga.

Verawati, N.D. 2009. Yoghurt Asam, Fresh, Sarat Manfaat. Jakarta: Armandelta Selaras.

Waluyo, L. 2007. Mikrobiologi Umum. Malang: Universitas Muhammmadiyah Malang. 